\title{
PROGRESS IN SEPARATING PLASTIC MATERIALS FOR RECYCLING
}

\author{
G. DODBIBA* and T. FUJITA \\ The University of Tokyo, Department of Geosystem Engineering, \\ Graduate School of Engineering, 7-3-1 Hongo, Bukyo-ku, Tokyo 113-8656, Japan
}

(Received in final form 19 October 2004)

\begin{abstract}
In order to deal with the problems facing the plastics processing industry research, work is focused primarily on designing, developing and testing a variety of separation and sorting techniques able to recover plastics from wastes, which can be re-used or re-processed to form new products. In this regard, technologies developed in mineral processing can be of great help. Various techniques for separating plastics materials have been recently developed. These techniques can be divided in two main categories, i.e. wet separating techniques and dry separating techniques. This paper presents the recent progress in separating plastics reviewing the potential of the available techniques.
\end{abstract}

Keywords: Plastic separation; Sink-float separation; Flotation; Air table; Triboelectric separator

\section{INTRODUCTION}

Nowadays, the world is moving steadily into the age of conservation with recycling as an integral part. Recycling is an old concept but only truly came into its own with the advent of the industrial revolution. Without recycling, the life circle of products merely becomes a series of events without a logical solution to the resource conservation, since the potentially useful materials can consequently become a hazard to environment.

According to the Plastic Waste Management Institute of Japan [1], in 2002, the amount of plastic products consumption in Japan reached about $1.09 \times 10^{7}$ tonnes/ year after running at about $1.00 \times 10^{7}$ tonnes/year from $1990 \mathrm{on}$. In relation to this, the total amount of plastic waste discharge was about $0.56 \times 10^{7}$ tonnes in 1990 rising to about $0.99 \times 10^{7}$ tonnes in 2000 (Fig. 1). However, only about $50 \mathrm{wt} \%$ of this discharged amount is reused for material recycling chemical recycling and energy recovery [1]. Waste plastics are consequently one of the main polluters, as they constitute $14.2 \%$ in weight (Fig. 2) or $46.5 \%$ in volume (Fig. 3) of Japanese municipal solid waste, (MSW) [2].

*Corresponding author. E-mail: dodbiba@race.u-tokyo.ac.jp 


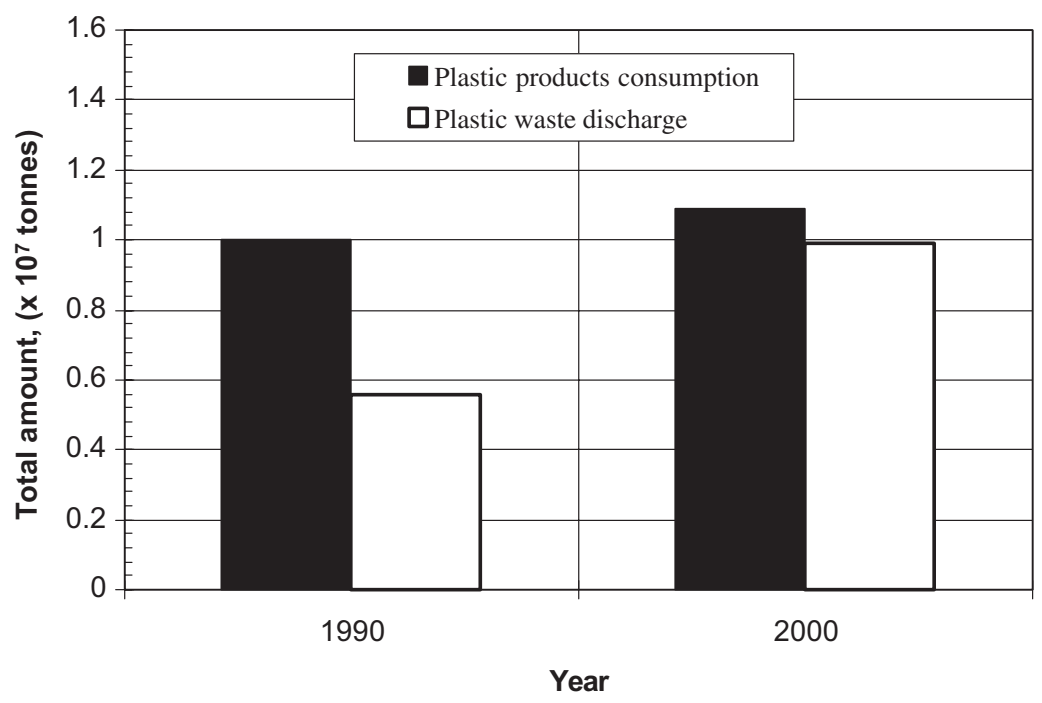

FIGURE 1 Consumed and discharged amounts of plastic materials in Japan.
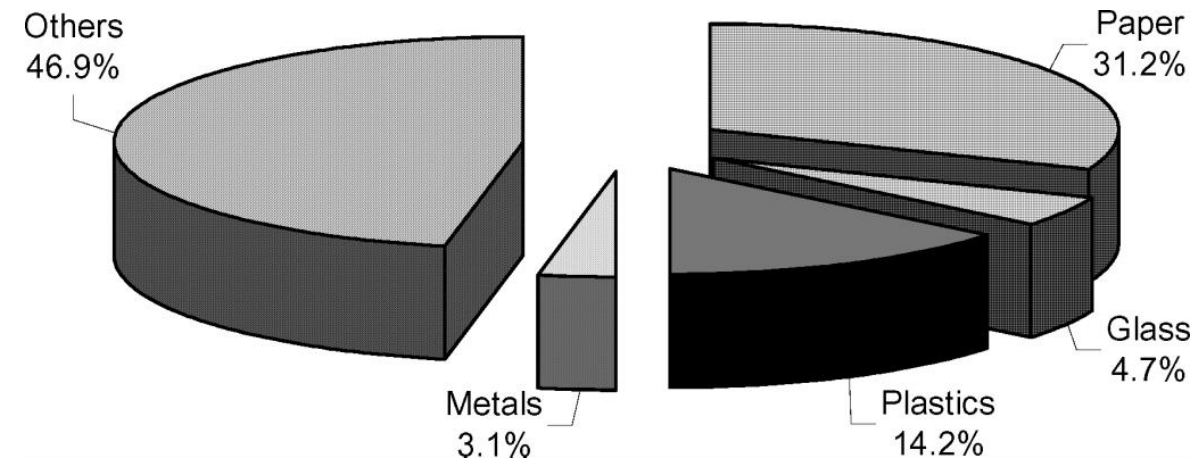

FIGURE 2 Breakdown (wt \%) of MSW in Japan (FY 2002).

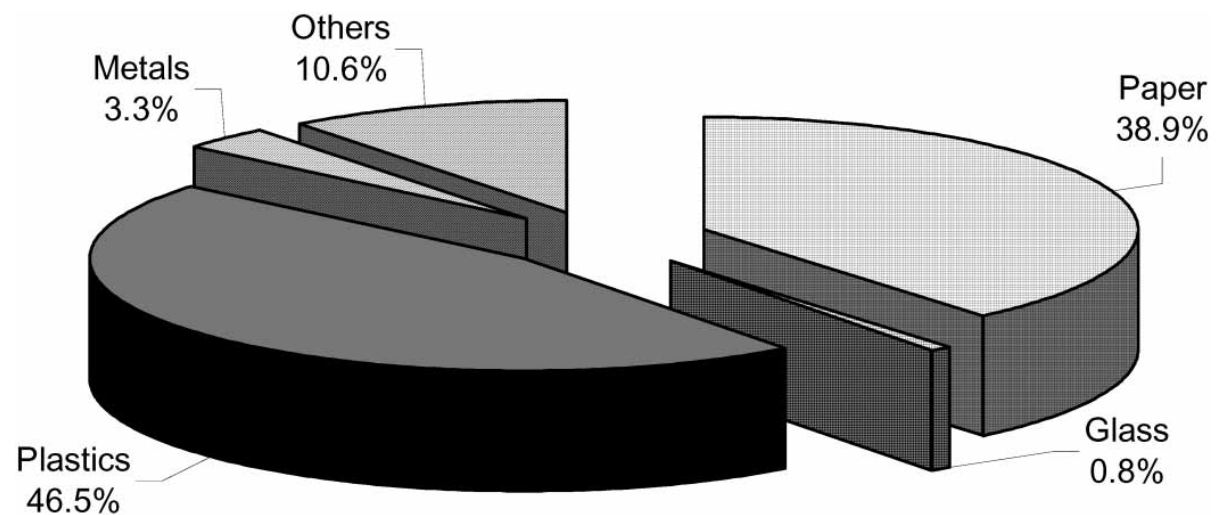

FIGURE 3 Breakdown (vol. \%) of MSW in Japan (FY 2002). 
TABLE I Utilization of various kinds of plastics.

\begin{tabular}{|c|c|}
\hline Type of resin & Utilization \\
\hline Acrylonitrile-butadiene-styrene (ABS) & $\begin{array}{l}\text { Has been mass-produced since 1960s. It is used in } \\
\text { electronic housings, telephone components, pipes and } \\
\text { fittings, computer housings (electroplated on the inside), } \\
\text { as well as automobile interior and exterior trim. }\end{array}$ \\
\hline Polyethylene terephthalate (PET) & $\begin{array}{l}\text { Developed in 1941. It is a very good material for carbonated } \\
\text { beverage applications and other food containers. PET also } \\
\text { finds applications in such diverse end-uses as fibres for } \\
\text { clothing and carpets, bottles, food containers and } \\
\text { engineering plastics for precision-moulded parts. }\end{array}$ \\
\hline Polystyrene (PS) & $\begin{array}{l}\text { Has been mass-produced since 1930. It is used for } \\
\text { inexpensive packaging materials, pens, safety razors, } \\
\text { electrical or electronic uses, building or construction, } \\
\text { flatware and jewel boxes. PS is also used extensively in } \\
\text { take-out restaurants for its lightweight, stiffness and } \\
\text { excellent thermal insulation. }\end{array}$ \\
\hline Polyethylene (PE) & $\begin{array}{l}\text { Has been mass-produced since } 1939 \text {. It is the largest } \\
\text { volume commodity plastic. PE is used in blow-moulded } \\
\text { beverage bottles, gas tanks, toys, fibres for clothing, etc. }\end{array}$ \\
\hline Polypropylene (PP) & $\begin{array}{l}\text { Has been mass-produced since the 1950s. It has excellent } \\
\text { resistance to water, salt and acid solutions that are } \\
\text { destructive to metals. Typical applications include } \\
\text { ketchup bottles, yogurt containers, medicine bottles, } \\
\text { medical syringes, beakers, automobile battery casings } \\
\text { and carpeting markets. }\end{array}$ \\
\hline Polyvinyl chloride (PVC) & $\begin{array}{l}\text { Has been mass-produced since } 1938 . \text { It is used in pipes } \\
\text { and fittings, wire and cable insulation, packaging, } \\
\text { medical applications, electrical or electronic uses, etc. }\end{array}$ \\
\hline
\end{tabular}
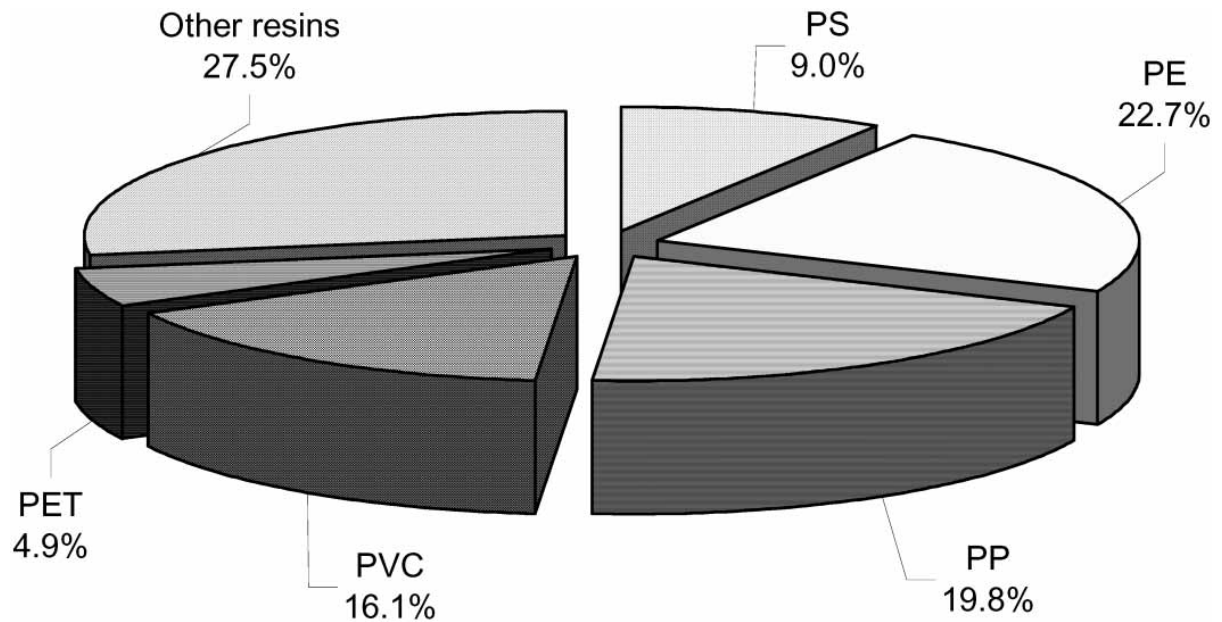

FIGURE 4 Breakdown of plastic production $\left(1.36 \times 10^{7}\right.$ tonnes) by resin type, in Japan (FY 2001) [3]. Note: production of PET is $0.066 \times 10^{7}$ tonnes [4].

Many kinds of plastics are in wide use today. Table I lists the main types of resins in use and their utilization. Moreover, breakdowns of plastic production, and plastic waste by resin type are shown in Figs. 4 and 5, respectively. Figure 4 shows that PE, and PP represent the largest volumes of commodity plastics, which are mainly used in packaging the industry (Table I), followed by PVC with 16.1\% [3,4]. Meanwhile, 


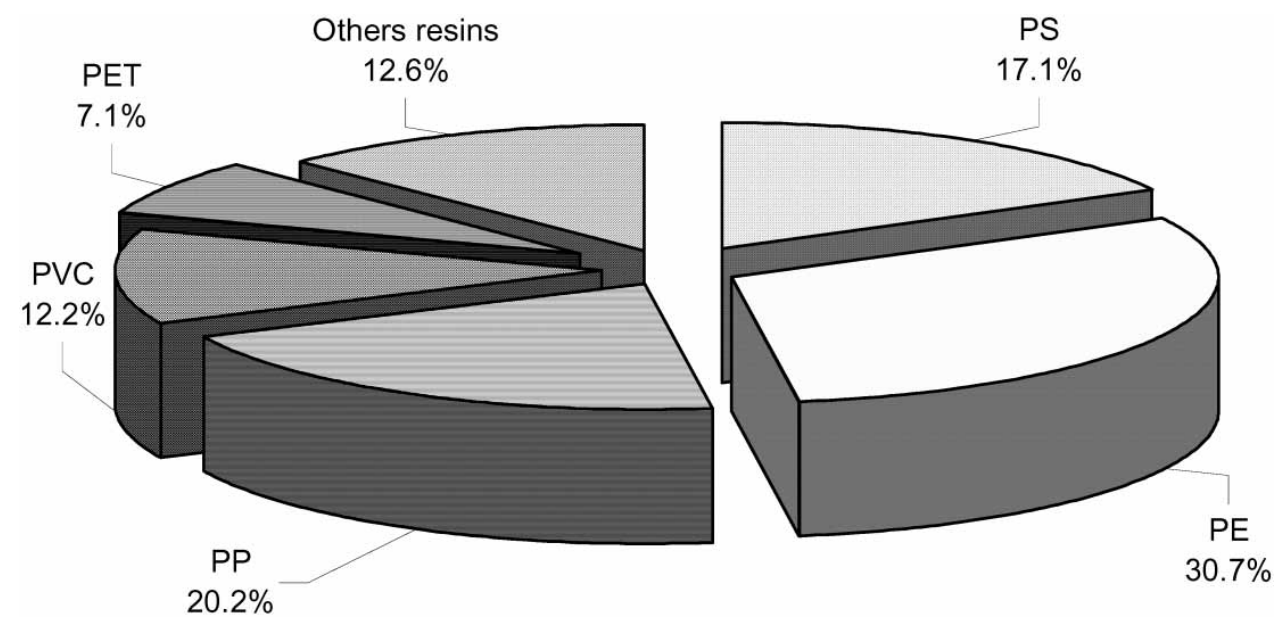

FIGURE 5 Breakdown of plastic waste discharge $\left(0.99 \times 10^{7}\right.$ tonnes) by resin type, in Japan (FY 2000) [1]. Note: the amount of waste PET is determined on the basis of the consumed amount, i.e. approximately $0.07 \times 10^{7}$ tonnes [4].

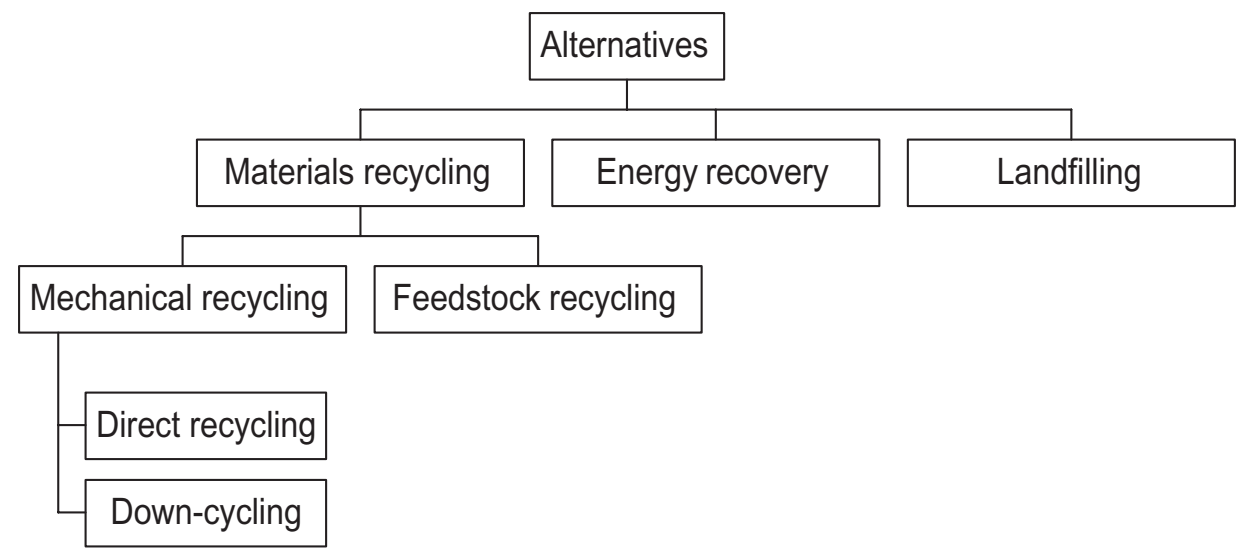

FIGURE 6 Alternatives for management of plastic wastes.

Fig. 5 shows that PE and PP are also the major sources of plastic waste, followed by PS and PVC with 17.1 and $12.2 \%$ respectively.

The growth of plastic waste has a negative impact on the environment. The potential reasons for this are that the available capacity for landfilling of wastes is declining and the incineration of plastics may cause the emission of harmful gases, together with generation of toxic fly and bottom ash that contain lead and cadmium [5].

In the view of the formation of a recycling-oriented society, several alternatives, with their specific advantages and disadvantages, are being considered for the control plastic wastes. At present, there are three main alternatives for the management of plastic wastes in addition to landfilling, as shown in Fig. 6:

(1) Mechanical recycling: the method by which waste plastics are recycled into new resources without affecting the basic structure of the material. It includes: (a) direct recycling to virgin plastic (i.e. high value end-product). It is the method for 
reprocessing separated plastic waste into the same or similar type of end product; and (b) down-cycling (i.e. low value end-product). It is the method for producing low quality plastics products where finish and appearance are relatively unimportant.

(2) Feedstock recycling: the term feedstock recycling encompasses chemical recycling but is most often applied to a range of plastics recovery techniques that break down polymers into their constituent monomers, which in turn can be used again in refineries or petrochemical and chemical production. For example, pyrolysis and gasification processes have been developed to thermally degrade plastic waste, producing hydrocarbon fractions that may be used as a chemical feedstock or further refined into a fuel. In another example, the plastics are sometimes used as a direct replacement for petroleum in oil refineries, where the mixture of organic compounds produced by pyrolysis is then fractionated into purer, more valuable products [6].

(3) Energy recovery: the recycling method in which thermal energy is recovered from waste plastics. The option includes direct incineration with energy recovery, production of refuse derived fuel (RDF) and packaging derived fuel for incineration; or direct incineration as a fuel. Here, the energy content of the plastic is recovered at temperatures above $1450^{\circ} \mathrm{C}$.

It is important to note that energy recovery, although an efficient alternative for the removal of plastic wastes, is the subject of great public concern due to the contribution of combustion gases to atmospheric pollution. Moreover, energy recovery is a consumptive recycling process (i.e. it turns the recycled material into energy rather than into usable material), and thus does not conform to the reuse-ratio requirement of the Japanese law on recycling [7]. On the contrary, mechanical recycling and feedstock recycling are closer to the ideal in that they produce materials that can be reused. Nevertheless, mechanical recycling requires high degree of sorting and separation. Feedstock recycling, on the other hand, appears as a potentially interesting approach. However, this method is expensive and relatively unproven, output market for pyrolysis oil is still under development and gas-cleaning issues are being researched. Of the two methods (i.e. mechanical recycling and feedstock recycling), mechanical recycling is especially effective because it uses less energy and has a smaller environmental impact than feedstock recycling [7]. In addition, capital investment requirements into feedstock recycling methods are much higher than requirements for mechanical recycling plants. Consequently, the mechanical recycling is favourable provided that via advanced separation technologies a high-quality recycling can be reached.

\section{TECHNOLOGIES FOR SEPARATING PLASTICS}

As the raw mixture usually includes various kinds of waste plastics, this makes the separation an important process that should be carried out prior to recycling. However, separation of mixed plastics encounters many problems (due to the characteristics of plastics) and represents one of the most problematic processes in the management system of plastic waste.

For example, it is difficult to distinguish shredded bottles of polyvinyl chloride (PVC) from shredded PET bottles. Despite that, the separation of PVC from PET should 
TABLE II Required purity of sorted plastics for reuse [9].

\begin{tabular}{lc}
\hline Destination & Required purity \\
\hline Reuse of plastics in circulating system as low quality plastics & $>95.0 \%$ \\
Reuse of plastics in circulating system as virgin plastics & $>99.5 \%$ \\
Reuse of plastics for agricultural, horticultural industry, etc. & $>99.0 \%$ \\
Use of plastics as oxidant in blast furnaces & $<1.0 \%$ (PVC impurity) \\
\hline
\end{tabular}

always be carried out in advance, as even a small concentration of PVC in a melt of PET can substantially decrease the quality of the whole batch. In another example, steel companies in Japan have recently planned to utilize waste plastics instead of fine coals for charging into blast furnaces. However, this leads to the question of the longterm furnace corrosion from increasing levels of PVC in waste plastics, since about two thirds of the chlorine produced from incineration of PVC appears as hydrochloric acid in flue gas with a reminder being retained by the ash [8]. Considering these examples, it is understandable why purchasers of plastics as secondary raw materials require that the mixed plastics be sorted properly (Table II) [9].

To deal with the problems that the plastics processing industry is facing, the research work is focused primarily on designing, developing and testing a variety of separation and sorting technologies able to recover valuable materials from wastes, which can be re-used or re-processed to form new products. In this regard, technologies developed in mineral processing can be of great help.

\subsection{Wet Separating Techniques for Separating Plastics}

One of the earliest publications on the separation of mixed plastics dates back to the early 1970s and originates from Japanese researchers that developed plastics flotation [10]. In 1976, Saitoh et al. [11] reported flotation of mixed plastics utilizing selective wetting characteristics in order to change the surface of specific plastics from hydrophobic to hydrophilic. Using this technique, plastics were collected with recovery higher than $95 \%$ and purity higher than $97 \%$. Kounosu et al. [12] also studied flotation of plastics. Employing polyvinyl alcohol (PVA) of relatively low degree of polymerization, he reported a successful separation of PP from PE.

Later, Shibata et al. $[13,14]$ successfully separated four different types of plastics, namely polyvinyl chloride (PVC), polycarbonate (PC), polyacetal (POM) and polyphenylene (PPE), using common wetting reagents like sodium ligninsulfonate, tannic acid, Aerosol OT and saponin. At first, floatability of individual plastics was measured by means of column flotation in the presence of various depressants, and a three-step process was then developed. The first step of the process involved heavy media separation to obtain a float product of PPE having purity and recovery of $100 \%$, respectively. Subsequently, the PVC concentrate of $95.7 \%$ purity was separated by flotation during the second step using sodium lignin sulfonate depressant. Finally, the float product with $87.6 \%$ POM and the sink product with $90.3 \%$ PC were obtained at the third step of the process by means of flotation in the presence of a saponin/Aerosol OT combination. Meanwhile, Fraunholcz et al. [15] conducted several flotation experiments using different surfactants. His findings indicated that the absorption of depressants on plastics was mainly driven by hydrophobic interaction and electrostatic forces. Consequently, he suggested that adsorption-based wetting of plastics can be expected 
with high-molecular-weight, i.e. macromolecular depressants. Moreover, Guern et al. [16] performed flotation of PVC/PET mixture after selecting suitable reagents. The selection of reagents was based on the studies of the behaviours of PVC and PET during grinding process using different type of mills, surface morphology after grinding, and surface chemistry. Separation of PET/PVC mixture was also reported by Drelich et al. [17], who demonstrated that by using froth flotation $95-100 \%$ recovery of PET or PVC can be achieved in separated products.

In 1997, Stuckrad et al. [18] developed a new dry-physical conditioning process by plasmaactivation of the plastic surface as an alternative to chemical conditioning. It was reported that this new conditioning method allowed the same sorting quality, but its emission of pollution was much lower. Furthermore, the results showed that by only one step of flotation, the purity of collected products was higher than $99 \%$ and the recovery was between $80-90 \%$.

After reviewing the flotation of plastics [19] and discussing the relation of floatability of PVC and PMMA (polymethyl methacrylate) mixture with surface chemical related and gravity factors, Shen et al. [20] suggested that plastic flotation is a combination of froth flotation and gravity separation. Accordingly, the idea of particle control was applied for separation of mixed plastics. The experimental results showed that PVC and PMMA products were selectively separated by flotation. The recovery, and the purity of each collected product was higher than $98 \%$ respectively. Subsequently, they investigated the floatability of seven other types of plastics (including PVC, PET, PS and ABS) in the presence of methylcellulose and separated them into various groups. Accordingly, the results of flotation of plastics within the same group were limited, due to their small differences in floatability, whereas flotation of plastics of different groups was achieved with recovery generally higher than $99 \%$ and purity higher than $95 \%$ [21].

Pascoe et al. [22] also developed a method for separation of PVC and PET using flame treatment and flotation. Flame treatment was used to modify the surface of plastics to allow water-based coatings to be applied. The effect of the treatment was therefore to produce hydrophilic species on the surface of the plastics. The flame treatment involved the use of an acceleration chute that delivers the flakes through the flame of an angled burner. Then, a combination of a two-stage flotation process, and flame treatment was tested for the separation of PET. In the first stage, the PET was floated away from the PVC utilizing differences in particle thickness and surface contamination. The float product was then subjected to flame treatment and hydrophobic recovery prior to the second stage of flotation. In this stage, the PVC was reported to the float product leaving a PET-rich sink fraction. Nevertheless, it was reported that the efficiency of the process needs to be improved before being of commercial interest.

Italian researchers studied the wet density separation of different types of virgin plastics using a dynamic medium separation system. Plastic separation using this method required media with low density, say around $1000-1300 \mathrm{~kg} / \mathrm{m}^{3}$. For this purpose the most utilized media were: water and water solutions of calcium chlorite, sodium chlorite, calcium nitrate and ethyl alcohol. The process was tested on a PS/PP mixture using a two-stage Tri-Flo separator of $100 \mathrm{~mm}$ in diameter and water as medium (Fig. 7). The results were satisfactory as the PP content in the float products was $99.9 \%$ [23,24].

Moreover, the behaviour of PVC and PET in a LARCODEMS dense medium separator (Fig. 8) has been investigated using calcium chloride solutions as the medium [25]. It has been shown that particle thickness and surface conditioning can 
Feed

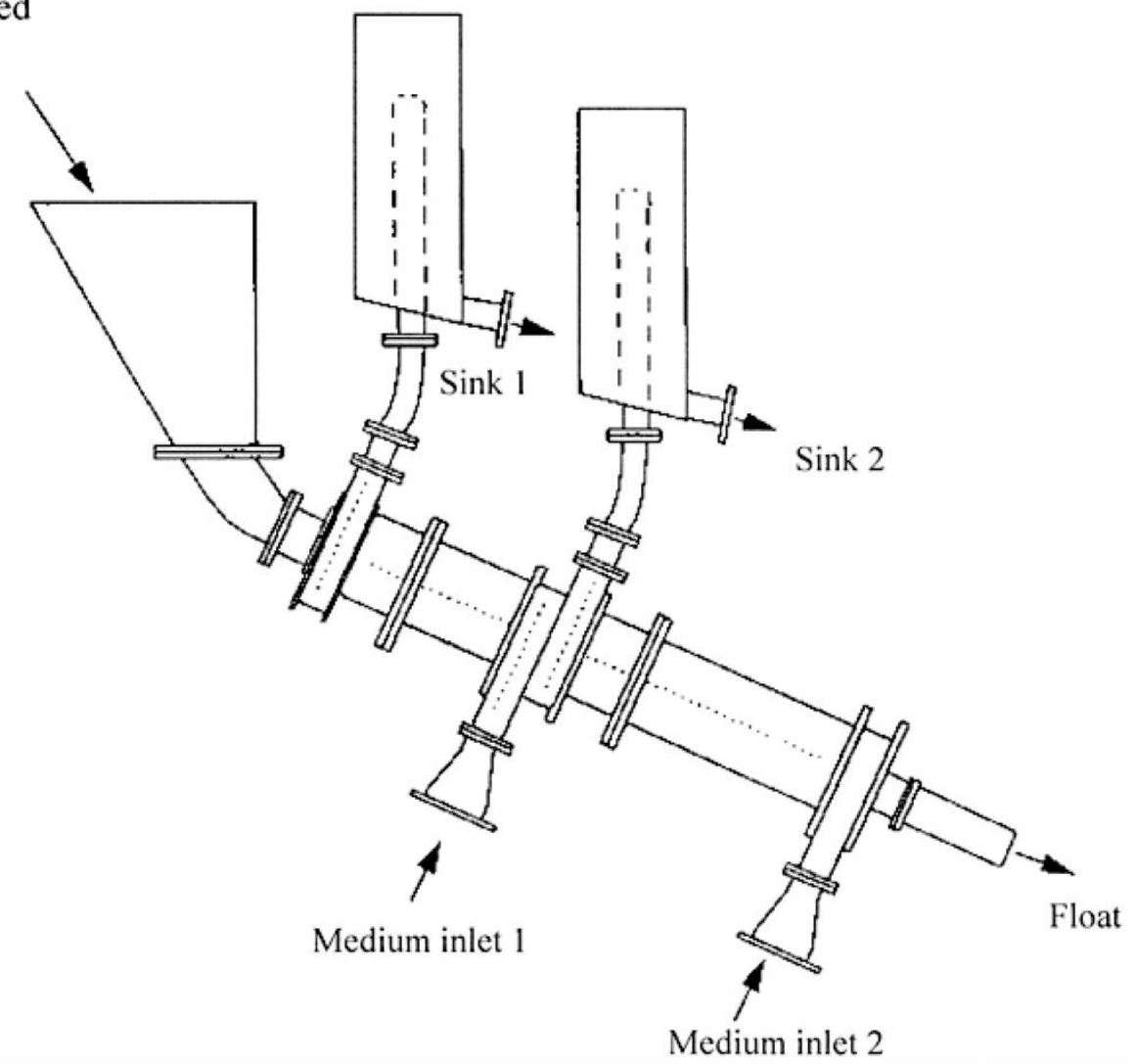

FIGURE 7 Schematic design of Tri-Flo separator.

have a significant influence on plastic behaviour within the separator. Thus, given the complexity of a mixture of shredded plastics in terms of size, shape and thickness, density separation using the LARCODEMS is likely to be only considered as a preconcentration step.

Tsunekawa et al. [26] employed a TACUB jig (Fig. 9) to separate plastics from scrap electric wires. Thus, he carried out separation of PVC from PE collecting products with purities higher than $98 \%$. Based on the experimental results, he reported that the upstream speed and the amplitude of the pulsation of the water were the main parameters that influenced the efficiency of the separation process.

Furthermore, sink-float separation techniques are well-known wet methods for separation of mixed plastics. Shimoiizaka et al. [27] satisfactorily separated various mixtures of plastics of different densities by using a laboratory-scale sink-float separator. They reported that the impurity of each separated product was than $1 \%$. Later, the separation of PET/PE and PET/PP mixtures was carried out in order to improve the purity of the raw input used in PET bottle recycling [28,29]. Initially, PET bottles and their caps (made of PE or PP) were shredded and the floatability of each polymer was tested. Since the results did not suggest that the required purity of PET plastic could be achieved by floatation (even with the addition of the wetting reagents dodecylamine acetate or polyvinyl alcohol), the mixtures were then processed in a sink-float process 


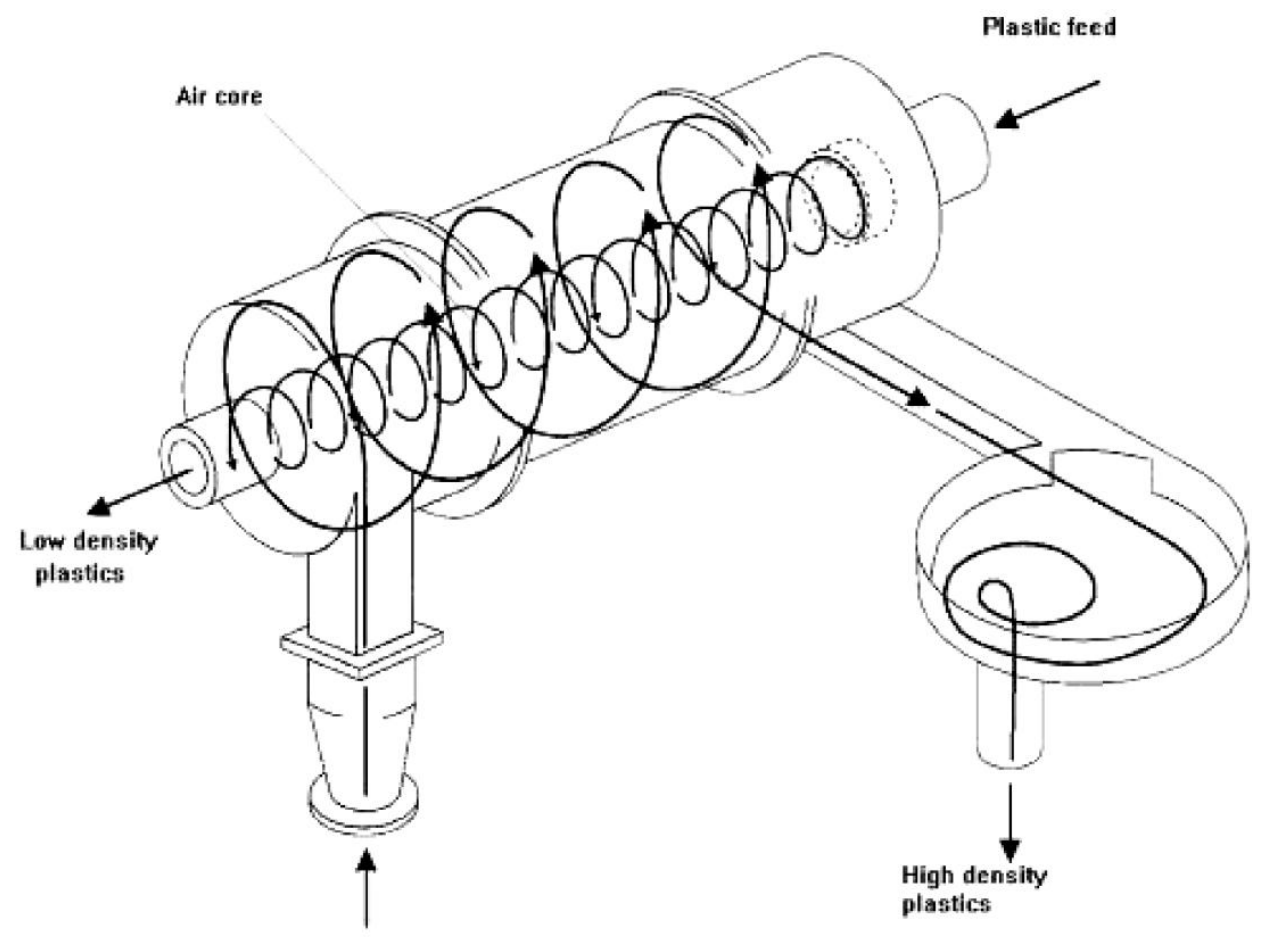

Medium inlet

FIGURE 8 Diagram to illustrate the operation of a LARCODEMS separator.

using a drum-type sink-float separator. Finally, as the required purity of PET could not be obtained by either technique alone (i.e. neither flotation nor sink-float separation), a system utilizing a combination of the two processes was devised (Fig. 10). This system easily achieved the desired purity PET i.e. higher than $99.995 \%$.

Although wet separation techniques provide adequate recoveries, they have clear disadvantages over dry ones, since some potential problems associated with wet separating methods in general, such as: (1) treatment of water from the process for reuse or discharge; (2) the requirement of expensive wetting reagents, and most importantly, and (3) dewatering or drying the mixture after separation cannot be avoided. In this regard, dry separation processes offer economical alternatives.

\subsection{Dry Separating Techniques}

In 1992, Dinger [30] conducted automatic sorting of PET and PVC plastic bottles utilizing a conveyor, resin/colour detector and air jet ejector. Conventionally, in the automatic plastics sorting system, it is common to use equipment applying near-infrared spectroscopic analysis with diffraction grating [31], acoust-optic tunable filter [32], or an optical filter [33]. Equipment applying Fourier transforming infrared spectrometry [34], Raman spectrometry [35] or infrared absorption using InGaAsP laser diode [36,37] are also used. Although these devices offer high accuracy, they are not always suitable for current sorting system from the viewpoint of cost-efficiency and handling [37]. 


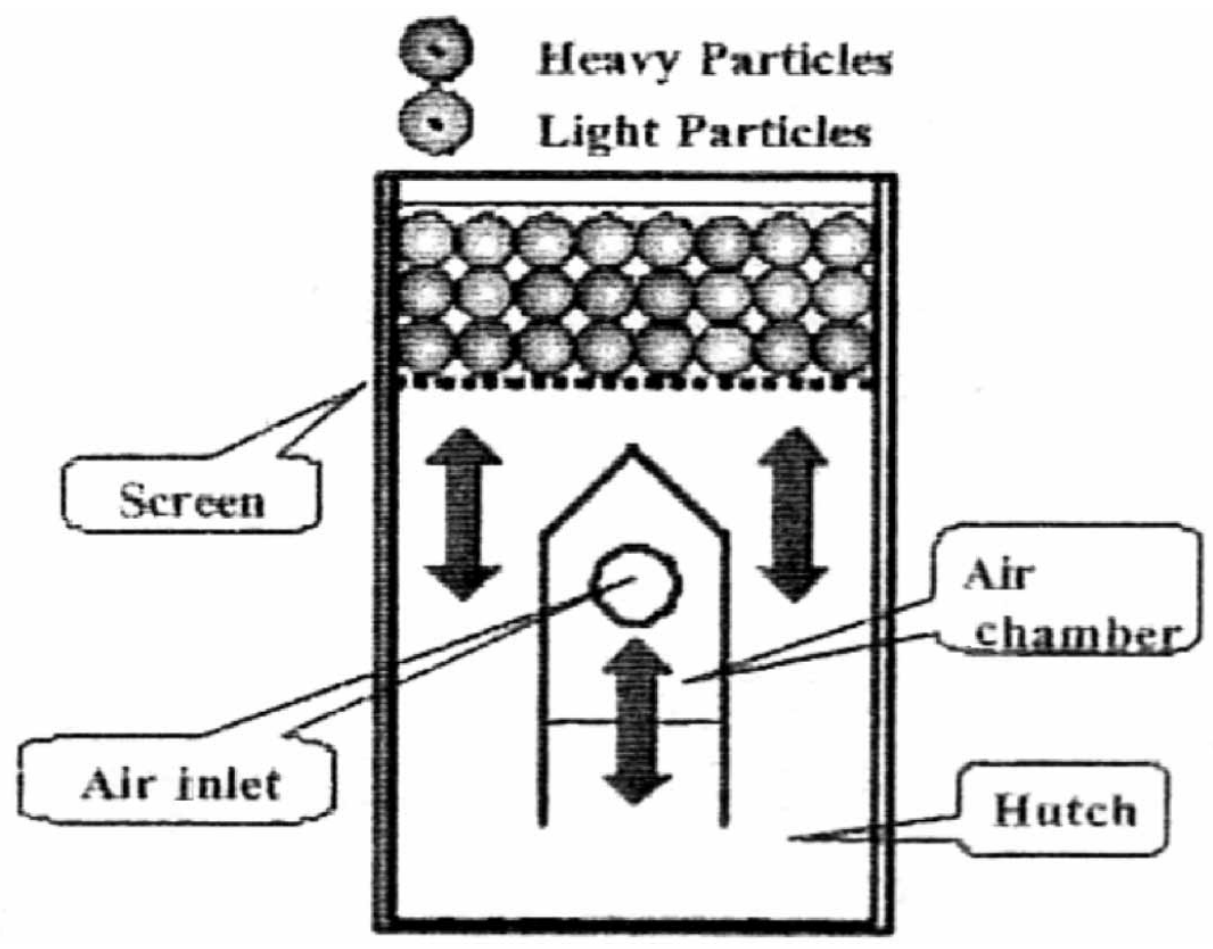

FIGURE 9 Schematic design of TACUB jig.

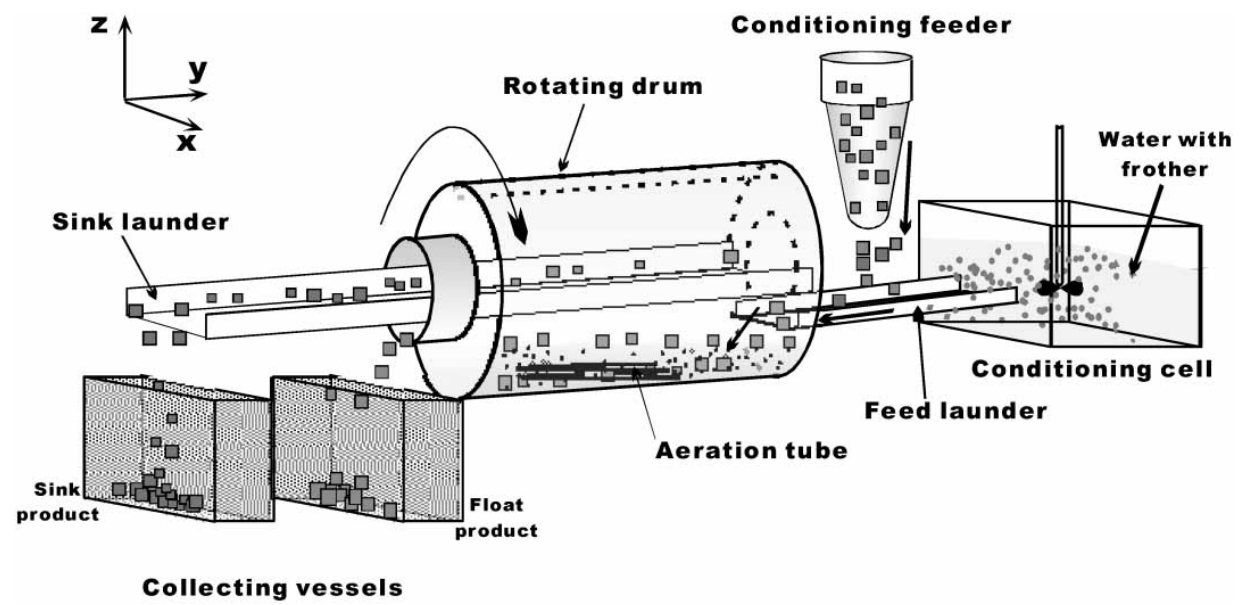

FIGURE 10 Schematic design of the drum separator that uses the combination of sink-float separation and flotation.

Generally speaking, dry gravity separation has the attraction of low capital input and operating cost which together with the lack of water, chemicals and drying requirements means it is environmentally friendly [38]. In the field of waste processing, if there is a difference in density between materials, vertical air classifiers have a history 
of being very effective devices. Arai et al. [39] used a column-type air separator for dry separation of other plastics from PVC, which contains chlorine that damages incineration furnace. By using this technique, PVC product was collected with recovery generally higher than $80 \%$. In 1999, Ito et al. [40] performed a feasibility study on separation of mixed plastics of different densities using a new type of pneumatic separator with acceleration-deceleration zones. Diskshaped plastics of PVC, PC and PP having thickness of around $2 \mathrm{~mm}$ and diameter of $10 \mathrm{~mm}$ were tested. Later, Nakajima et al. [41] carried out air separation of PET and PVC by taking advantage of different crushing resistance of two plastics. PET bottles and PVC sheet (thickness of $0.5 \mathrm{~mm}$ ) were shredded to small pieces with a shear-type crusher. After crushing for $90 \mathrm{~s}$, PET shreds, which were bent and twisted by the crush, were blown up (air flow rate of $3 \mathrm{~m} / \mathrm{s}$ ), whereas PVC shreds were collected as sink product, the recovery of collected products was $100 \%$. However, the uses of air classifiers in the separation of mixed plastics are limited due to a small density differential between plastics to be processed.

Generally, vertical air classifiers are not considered to have a simple design [42], since they need to be connected with a device (commonly a cyclone) in order to subsequently separate the low-density fraction entrapped in the air stream from air (Fig. 11). Moreover, these air classifiers, which generally do not allow for separation into more than two fractions (known as extract and reject), require a large working space (because of their considerable height) and are not an answer where the space is at premium. With this in mind, Dodbiba et al. [44] investigated the performance of the air table when separating a PVC/PP mixture. The air table is more compact device with a simpler geometry (Fig. 12), since unlike the vertical air classifiers, it does not require separating the low-density fraction from the air stream and is capable of effectively treating plastics of different densities. Based on numerous tests, he reported that the purity of PVC

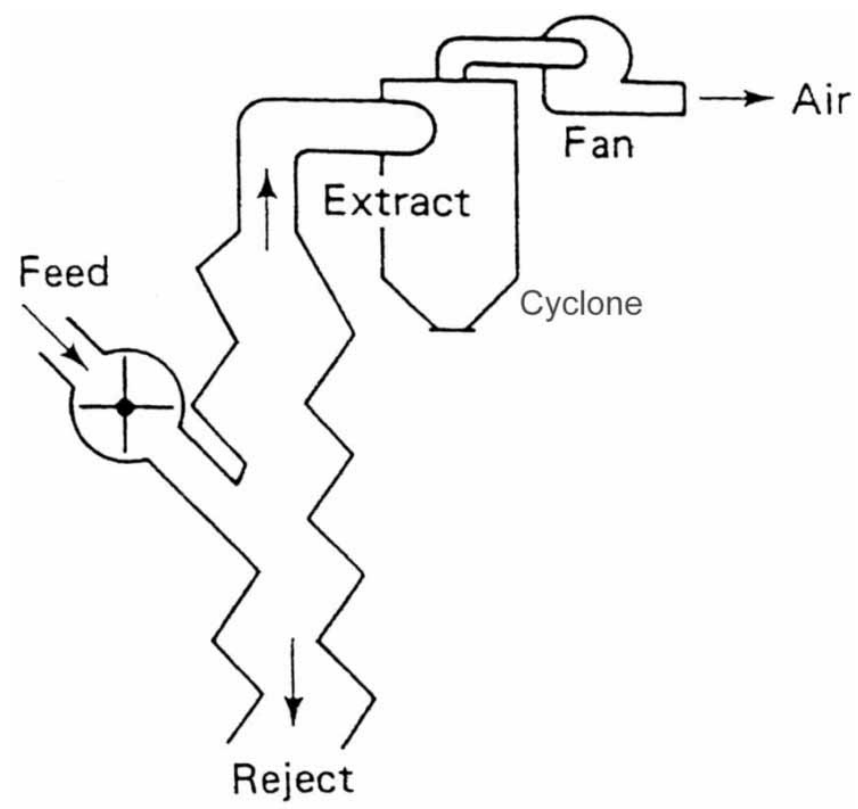

FIGURE 11 A basic arrangement for separation by zigzag air classifier [43]. 


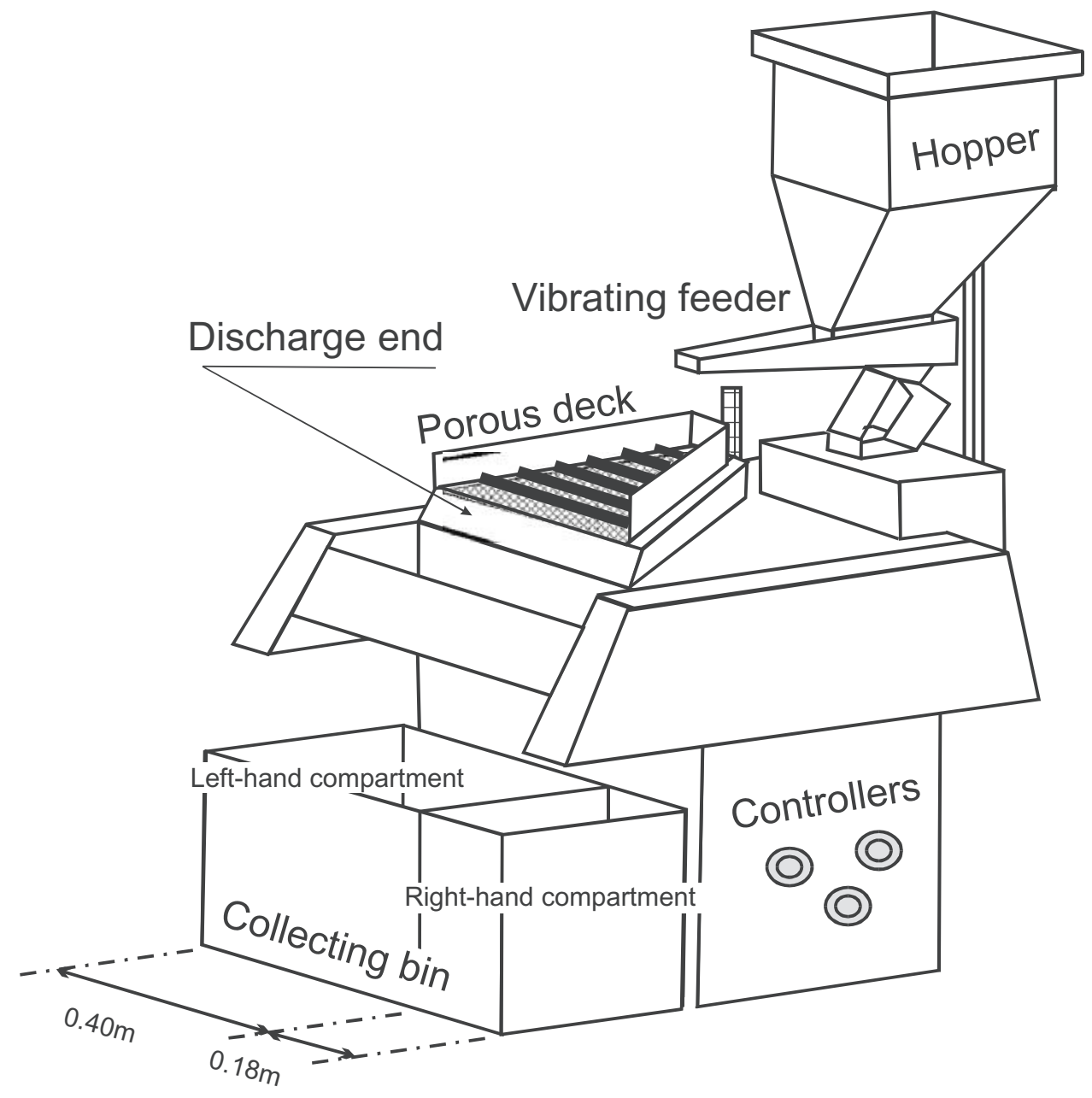

FIGURE 12 Schematic design of air table.

and PP products was $99.90 \%$ and $95.84 \%$ respectively, while the recoveries were higher than $96.70 \%$.

Moreover, electrostatic separation by means of corona charging has been successfully applied to separate metal/non-metal mixtures, i.e. aluminium or copper from plastics or paper [45-49]. Furthermore, a technique that makes use of the eddy currents is also employed to separate plastic particles from a metal/plastic mixture [50,51]. However, these techniques are only applied to separate good conductors (such as metallic particles, etc.) from dielectrics, as they are unable to separate a mixture of dielectric particles such as mixed plastics.

Triboelectric separation (i.e. a kind of electrostatic separation that utilizes frictional charging) is the technique most frequently used to selectively separate two solid species of dielectric materials. Nevertheless, application of triboelectric separation of plastics is relatively new. One of the earliest publications on this subject dates back to the early 1990s and originates from Canadian researchers that developed a triboelectric fluidizing bed (Fig. 13) for separation of different binary plastic mixtures [52]. The experimental 


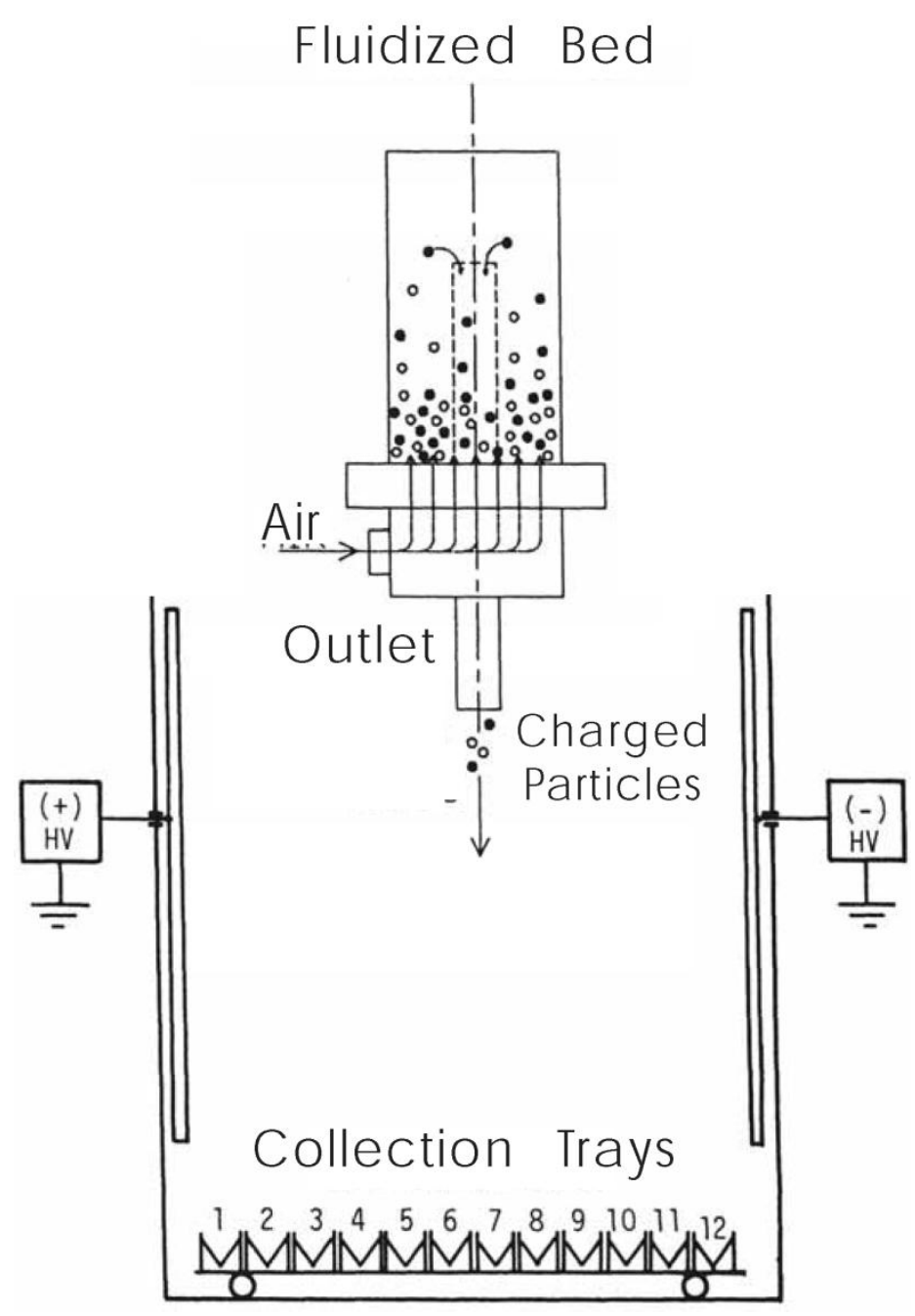

FIGURE 13 Fluidized bed triboelectric separator.

results showed an effective triboelectric separation of acrylic, nylon PE or PVC, achieving a purity of $95 \%$ or more. Later, triboelectric charging of plastics by vibrating chute (Fig. 14) was also reported [53,54]. Moreover, Matsushita et al. [56] triboelectrically sorted mixed plastics by means of a rotating drum (Fig. 15), which was comprised of a cylinder with rotary blades, whose form was adapted to enhance mutual friction between plastic pieces. He reported that a mixture of two kinds of plastics was successfully separated and the purity of products was not less than 90\% (Matsushita et al.). Later, Takeshita et al. [58] devised a triboelectric separator for continuous separation of PVC sheets from other plastics. The apparatus consisted of a triboelectric section (which included two fluidized beds) and an electrostatic separating section. The mixture of plastic sheets was initially triboelectrified in the first fluidized bed and then introduced to the second one, where plastics were blown off into the electrostatic 


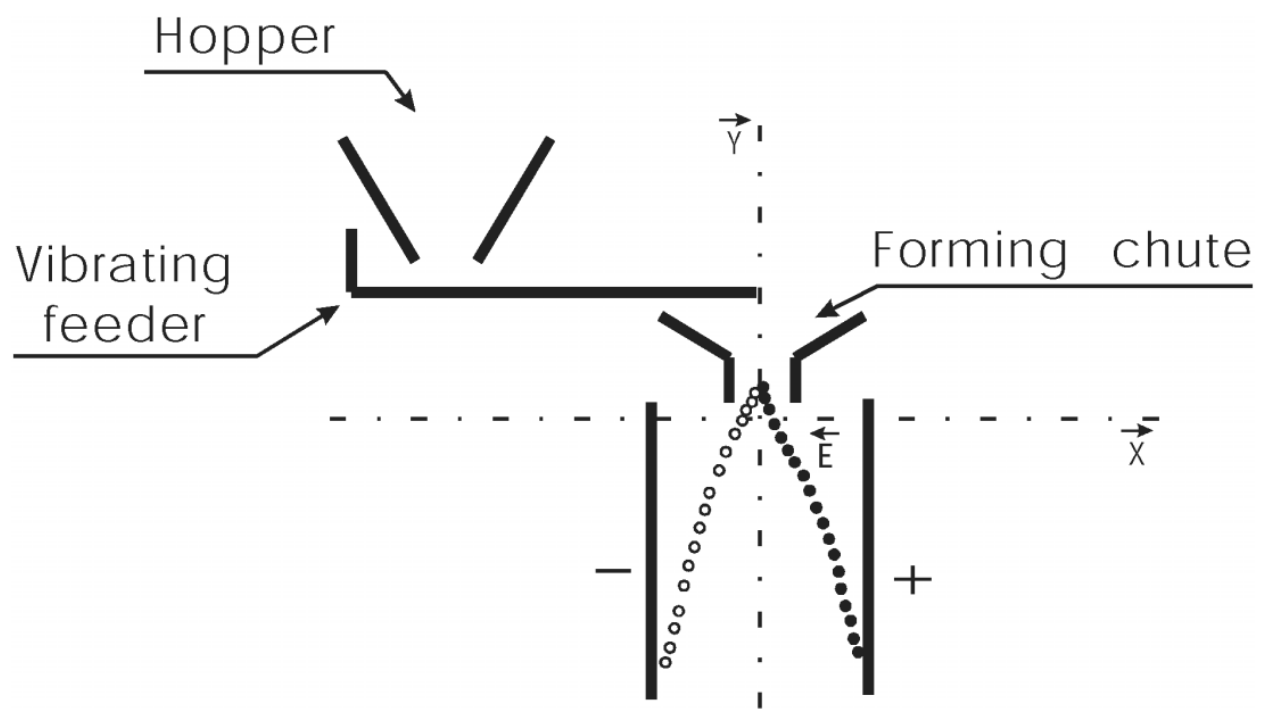

FIGURE 14 Vibrating chute triboelectric separator [55].

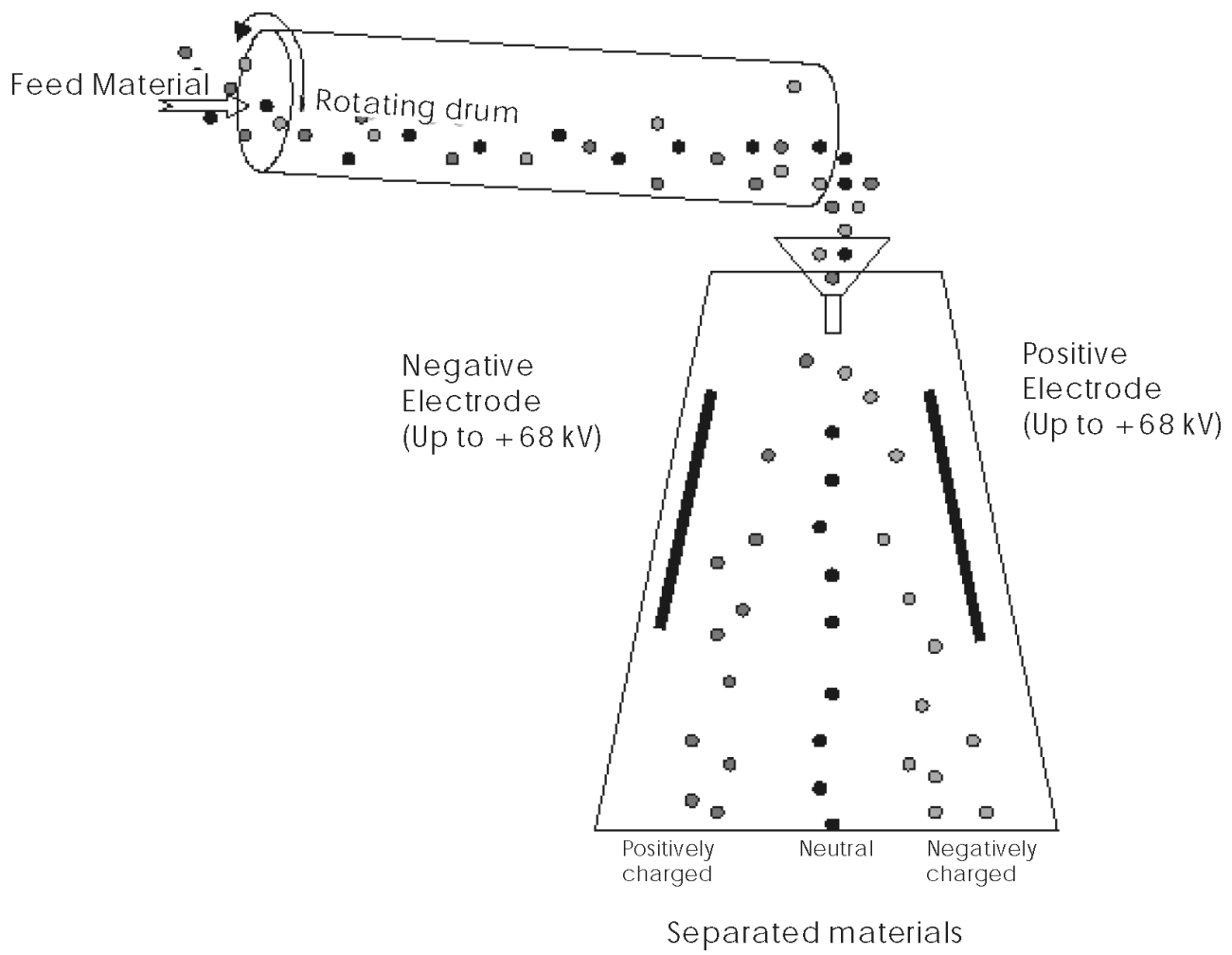

FIGURE 15 Rotating drum triboelectric separator [57]. 


\section{Airflow regulator}

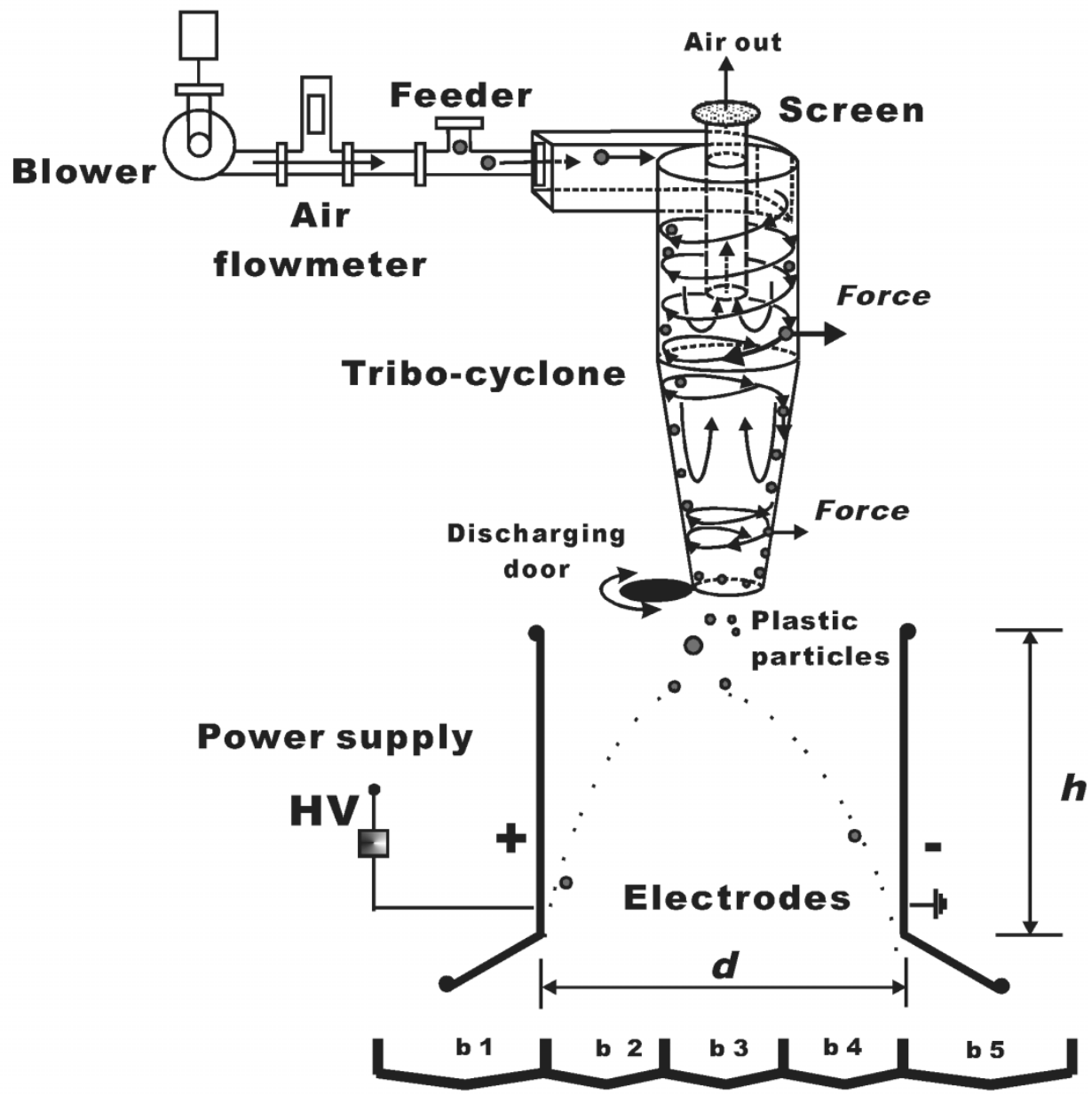

\section{Collecting bins}

FIGURE 16 Schematic design of triboelectric cyclone separator.

separating unit (electric field strength of $150 \mathrm{kV} / \mathrm{m}$ ). At the end of the process, the recovery and the purity of collected PVC product was higher than $70 \%$ and $90 \%$ respectively.

It can be noted that triboelectrification of mixed plastics is usually accomplished by one of the following charging devices: fluidized-bed (Fig. 13), vibrating chute (Fig. 14), or rotating drum (Fig. 15). As these devices tend to give rather low surface charge because the charging is primarily due to particle-particle contact, and the frictional speed is relatively low [59], Rodbiba et al. [60] employed an air cyclone as a charging device to produce a higher frictional speed. He developed a triboelectric cyclone separator (Fig. 16), which has been successfully tested in the laboratory for separating plastics. Considering his experimental results, the recovery of each collected product was higher than $75 \%$ while the purity was higher than $95 \%$. 


\section{SUMMARY}

An important subject in society is now to minimize the amount of plastic waste for environmental health or elongation of service life of disposal sites. As the raw mixture usually includes various kinds of waste plastics, this makes the separation an important process in terms of sustainable recycling.

To deal with the problems that the plastics processing industry is facing, the research work is focused primarily on designing, developing, and testing a variety of separation and sorting techniques able to recover plastics from wastes, which can be re-used or re-processed to form new products. In this regard, technologies developed in mineral processing can be of great help.

Various techniques for separating plastics materials have been recently developed. These techniques can be divided in two main categories, i.e. wet separating techniques and dry separating techniques. This paper presents the progress in separating plastics, reviewing the potential of the available techniques.

\section{Acknowledgments}

The financial support provides by Japan Society for the Promotion of Science through its JSPS Postdoctoral Fellowship Program is gratefully acknowledged.

\section{References}

[1] Plastic Waste Management Institute of Japan, PWMI Newsletter, 24 (2002), Available at: http:// www.pwmi.or.jp/ei/

[2] Environmental Agency in Japan, Finance Ministry Printing in Japan, Kankyou Hakusho (2002), 174. (In Japanese.)

[3] Japan Almanac 2003. The Asahi Shinbun (2003), 139.

[4] Japan Plastics Industry Federation, Japan Plastics, 3 (2003), 28-30, 58-59, Available at: http:// www.jpif.gr.jp (In Japanese.)

[5] T.R. Curlee and S. Das, Plastics Wastes (Management, Control, Recycling and Disposal), Noyes Data Corporation, New Jersey, NJ, 1991.

[6] H. Bockhorn, J. Hentschel, A. Hornung and U. Hornung, Environmental engineering: stepwise pyrolysis of plastics waste, Chemical Engineering Science, 54 (1999), 3043-3051.

[7] O. Murakami, Technology for recycling plastics materials, Mitsubishi Electric Advance Magazine, Environmental Technology Editions, 96 (2001), 6-9, Available at: http://global.mitsubishielectric.com/ company/r_and_d/advance/2001.html

[8] F.S. Kaufman, Jr, Opportunities for plastics in resource recovery, Resource Recovery and Utilization, ASTM STP 592, American Society for Testing Materials (1975), 122-131.

[9] KINKI KOGYO Co. Ltd., Japan - Private communication, May, 2002.

[10] J. Shimoiizaka, A. Kounosu and Y. Hayashi, Fundamental research on wet separation of waste plastics by combination of sink-float separation and flotation, Journal of Mining and Metallurgical Institute of Japan, 90 (1974), 775-779. (In Japanese with English abstract.)

[11] K. Saitoh, I. Nagano and S. Izumi, New separation technique for waste plastics. Resource Recovery and Conservation, 2 (1976), 127-145.

[12] A. Kounosu, Y. Hayashi and K. Saito, Separation between polypropylene and polyethylene by means of flotation, Journal of Mining and Metallurgical Institute of Japan, 94 (1978), 475-478. (In Japanese with English abstract.)

[13] J. Shibata, S. Matsumoto, H. Yamamoto, E. Kusaka and Pradip, Flotation separation of plastics using selective depressants, International Journal of Mineral Processing, 48 (1996), 127-134.

[14] J. Shibata, S. Matsumota, E. Kusaka, H. Yamamoto and Y. Morimoto, Feasibility of flotation to separate waste material, Journal of the Mining and Materials Processing Institute of Japan, 112 (1996), 177-184. (In Japanese with English abstract.) 
[15] N. Fraunholcz and W. Dalmijn, Wetting mechanisms in the flotation of plastics. Proceedings of the XX International Mineral Processing Congress, Aachen, Germany, 21-26 September, 1997, 5 (1997), pp. 329-340.

[16] C.L. Guern, P. Conil and R. Houot, Physico-chemical separation (flotation) of plastics waste before recycling. Proceedings of the XX International Mineral Processing Congress, Aachen, Germany, 21-26 September, 1997, 5 (1997), pp. 319-327.

[17] J. Drelich, T. Payne, J.H. Kim and J.D. Miller, Selective froth of PVC from PVC/PET mixtures for the plastics recycling industry, Polymer Engineering and Science, 38 (1998), 1378-1386.

[18] B.T.O. Stuckrad, K. Lohr and V. Vogt, Sorting of waste plastics mixtures by flotation. Proceedings of the XX International Mineral Processing Congress, Aachen, Germany, 21-26 September, 1997, 5 (1997), pp. 307-318.

[19] H. Shen, R.J. Pugh and E. Forssberg, A review of plastics waste recycling and the flotation of plastics, Resources, Conservation and Recycling, 25 (1999), 85-109.

[20] H. Shen, E. Forssberg and R.J. Pugh, Selective flotation separation of plastics by particle control, Resources, Conservation and Recycling, 33 (2001), 37-50.

[21] H. Shen, E. Forssberg and R.J. Pugh, Selective flotation separation of plastics by chemical conditioning with methyl cellulose, Resource conservation and recycling, 35 (2002), 229-241.

[22] R.D. Pascoe and B. O'Connell, Development of a method for separation of PVC and PET using flame treatment and flotation, Minerals Engineering, 16 (2003), 1205-1212.

[23] P. Bevilacqua, P. Bozzato and G. Ferrara, Analysis of dense medium circuit for separating plastics. Proceedings of the XX International Mineral Processing Congress, Aachen, Germany, 21-26 September, 1997, 5 (1997), pp. 383-394.

[24] G. Ferrara, P. Bevilacqua, L.D. Lorenzi and M. Zanin, The influence of particle shape on the dynamic dense medium separation of plastics, International Journal of Mineral Processing, 59 (2000), $225-235$.

[25] R.D. Pascoe and Y.Y. Hou, Investigation of the importance of particle shape and surface wettability on the separation of plastics in a LARCOMES separator, Mineral Engineering, 12 (1999), $423-431$.

[26] M. Tsunekawa, K. Hori, T. Hirajima, H. Naoki and M. Ito, Application of jig separator to recycle plastics used in electrical appliances. Proceedings of Global Symposium on Recycling, Waste Treatment and Clean Technology, Madrid, Spain (REWAS '04), 2 (2004), pp. 1651-1660.

[27] J. Shimoiizaka, A. Kounosu, Y. Hayashi and K. Saito, A new type sink-float separator for waste plastics, Journal of Mining and Metallurgical Institute of Japan, 92 (1976), 675-679 (In Japanese with English abstract.)

[28] T. Fujita, N. Haruki, G. Dodbiba, P. Jing, T. Miyazaki and E. Kuzuno, Various kinds of plastics and paper separation using electrostatic separation and the combination of sink-float separation and flotation for recycling. Proceedings of the XXI International Mineral Processing Congress, 23-27 June, Rome, Italy, Vol. B (2000), pp. B12a-1-B12a-8.

[29] G. Dodbiba, N. Haruki, A. Shibayama, T. Miyazaki and T. Fujita, Combination of sink-float separation and flotation technique for purification of shredded PET-bottle from PE or PP flakes, International Journal of Mineral Processing, 65 (2002), 11-29.

[30] P. Dinger, Automatic sorting for mixed plastics, BioCycle, 33 (1992), 80-82.

[31] P. Williams and K. Norris, Near-infrared technology in the agricultural and food industries, St. Paul, MN: American Association of Cereal Chemists (1987).

[32] G. Lang, New on-line process analyzers expand NIR capabilities, Instrumentation and Control System, 64 (1991), 99-102.

[33] A. Pickuth, Advanced in bridging the gap between laboratory and process on- and in-line NIR spectrometry of liquids by the combined technologies of AOTF (acousto-optic tunable filter) remote sensing probes with fiber optics, sampling point multiplexing, and uses of chemometric software packages. In: Near Infrared Spectrometry. Horwood, Chichester (1992), pp. 153-158.

[34] M.P. Fuller and M.E. Meyers, Online FT-MIR/NIR process analysis. Microchemica Acta, 1 (1988), 31-34.

[35] J. Florestan, A. Lachambre, N. Mermilliod, J.C. Boulou and C. Marfisi, Recycling of plastics: automatic identification of polymers by spectroscopic methods, Resources, Conservation and Recycling, 10 (1994), 67-74.

[36] T. Tamon, S. Fujii, K. Inada, K. Motomura, I. Nishihara and T. Fujita, A proposal of plastic sensing by infrared absorption using laser diode. Proceedings of the 16th SICE (The Society of Instrument and Control Engineering) Symposium on Sensing Forum (1999), pp. 147-152. (In Japanese with English abstract.)

[37] K. Inada, R. Matsuda, C. Fujiwara, M. Nomura, T. Tamon, I. Nishihara, T. Takao and T. Fujita, Identification of plastics by infrared absorption using InGaAsp laser diode, Resources, Conservation and Recycling, 33 (2001), 131-146.

[38] A. Falconer, Gravity separation - old technique/new methods, Physical Separation in Science and Engineering, 12 (2003), 31-48. 
[39] S. Arai, S. Ito, E. Oi, H. Yotsumoto, E. Kikuchi and H. Sakamoto, Study of the dry separation of plastics using a column-type air separator. Proceedings of the Annual Meeting of MIMIJ (1995), p. 110. (In Japanese.)

[40] S. Ito, T. Hasuda and S. Arai, Plastics separation by pneumatic separator using differentiated acceleration-deceleration zone. Proceedings of 5th International Symposium on East Asian Recycling Technology, 15-17 June, Tsukuba, Japan (1999), pp. 273-276.

[41] J. Nakajima, H. Nakazawa, H. Sato and Y. Kudo, Study on air separation of PVC and PET. Journal of the Mining and Material Processing Institute of Japan, 117 (2001), 123-126. (In Japanese with English abstract.)

[42] R.I. Stessel, Recycling and resource recovery engineering - principles of waste processing, Springer, (1996), pp. 155-180.

[43] P.A. Vesilind and A.E. Rimer, Unit Operations in Resource Recovery Engineering, Prentice-Hall, 1981.

[44] G. Dodbiba, A. Shibayama, T. Miyazaki and T. Fujita, Separation performance of PVC and PP plastic mixture using air table, Physical Separation in Science and Engineering, 12 (2003), 71-86.

[45] M.R. Grubbs and K.H. Ivey, Recovering Plastics from Urban Refuse by Electrodynamic techniques. US Byreau of Mines, TPR 63, December (1972).

[46] S. Zhang and E. Forssberg, Optimization of electrodynamic separation for metals from electronic scrap, Resource, Conservation and Recycling, 22 (1998), 143-162.

[47] A. Iuga, R. Morar, A. Samuila, I. Cuglesan, M. Mihailescu and L. Dascalescu, Electrostatic separation of brass from industrial wastes. IEEE Transaction of Industry Applications, 35 (1999), 537-542.

[48] T. Fujita, M. Imai, N. Haruki, B. Jeyadevan, M. Miyazaki and A. Bekkala, Electrostatic separation of various kinds of plastics and papers. Proceedings of Fifth International Symposium on East Asian Recycling Technology, 15-17 June , Tsukuba, Japan, (1999), pp. 277-280.

[49] V. Gente, F.L. Marca, F. Lucci and P. Massacci, Electrical separation of plastics coming from special waste, Waste Management, 23 (2003), 951-958.

[50] S. Zhang, E. Forssberg, B. Arvidson and W. Moss, Separation mechanism and criteria of a rotating drum eddy-current separator operation, Resource, Conservation and Recycling, 25 (1999), 215-232.

[51] Z. Schlett, F. Claici, I. Mihalca and M. Lungu, A new static separator for metallic particles from metal-plastic mixtures, using eddy currents, Minerals Engineering, 15 (2002), 111-113.

[52] I.I. Inculet and G.S.P. Castle, Tribo-electrification of commercial plastic in air. Inst. Phys. Conf., Ser. No. 118: Section 4, paper presented at Electrostatics '91 (1991), pp. 217-222.

[53] T. Fujita, Y. Kamiya, N. Shimizu and T. Tanaka, Basic study of polymer particles separation using vibrating feeder and electrostatic high voltage generator. Proceedings of the Third International Symposium on East Asian Resources Recycling Technology (1995), pp. 155-164.

[54] M. Saeki, T. Inoue, M. Tukahara and H. Maehata, Vibro-electrostatic separation of plastics mixtures, Transactions of the Japan Society of Mechanical Engineers, 68 (2002), 14-20. (In Japanese with English abstract.)

[55] A.D. Moore, Electrostatics and its Applications, John Wiley and Sons, New York, 1973, pp. $221-249$.

[56] Y. Matsushita, N. Mori and T. Sometani, Electrostatic separation of plastics by friction mixer with rotary drum blades, Electrical Engineering in Japan, 127 (1999), 33-40.

[57] C. Xiao, L. Allen and M.B. Biddle, Electrostatic separation and recovery of mixed plastics. Paper presented at the Society of Plastics Engineers (SPE), Annual Recycling Conference (ARC) (1999). Available at: http://www.plasticsresource.com/s_plasticsresource/docs/900/852.pdf

[58] T. Takeshita, T. Harada, S. Takeichi and T. Saito, The continuous triboelectric separation for plastics sheets, J. Soc. Powder Technol., Japan, 37 (2000), 594-597. (In Japanese with English abstract.)

[59] J.A. Cross, Electrostatics: Principles, Problems and Applications, Adam Hilger, Bristol, 1987, pp. 17-90, 239-242.

[60] G. Dodbiba, A. Shibayama, T. Miyazaki and T. Fujita, Electrostatic separation of the shredded plastic mixtures using a tribo-cyclone, Magnetic and Electrical Separation, 11 (2001), 63-92. 